\title{
STIFFNESS OF COVER PLATE CONNECTIONS WITH SLOTTED HOLES
}

\author{
František Wald ${ }^{1}$, Zdeněk Sokol ${ }^{1}$, Matthieu Moal ${ }^{2}$, Vratislav Mazura ${ }^{1}$, Jean-Pierre Muzeau ${ }^{2}$ \\ ${ }^{1}$ Czech Technical University in Prague, CZ 16629 Praha 6, Czech Republic \\ ${ }^{2}$ Blaise Pascal University, LERMES / CUST, BP 206, 63174 Aubière Cedex, France
}

\begin{abstract}
This paper describes the prediction of stiffness of bolted cover plate connections with slots perpendicular to the acting force. The wok is based on three sets of tests: experiments on connections with more bolt rows and different bolt forming technology prepared at the CRIF laboratory in Liege, experiments with long slots finished at the laboratory of Technical University Nottingham, and experiments with components completed at the Czech Technical University in Prague. The work shows the application of the component method to the prediction of stiffness of the cover plate connections. The component bolt/plate in bearing is evaluated. A special attention is paid to the modelling of the bolt force distribution for different bolt tolerances.
\end{abstract}

Key Words: Steel structures, Bolted connections, Slotted holes, Cover plate connections, Experimental observations, Analytical modelling, Component method, Connection stiffness.

\section{Introduction}

Slotted holes are used in bolted connections of steel structures to compensate the tolerances during the erection, to allow one type of endplate for more connected members and to enable a slip in joint. Pre-loading of the bolts may prevent deformation of the connection in direction of the slot. Even smooth tightening of the non-preloaded bolts reach up to $20 \%$ of the tensile resistance of the bolt and together with the corrosion pretends structural use of the slip in the joint. The Fig. 1 shows the main difference of behaviour of bolts in slotted holes 
perpendicular to acting force compare to the bolts in circular holes - lower resistance and stiffness as well as higher deformation capacity of the connection.

Drilling, punching, or gas and plasma cutting form the holes. Punching of the holes in steelwork is faster than drilling but cracks may appear in the material. The holes are not punched to full size but $2 \mathrm{~mm}$ less in diameter and then reamed. New punching machines, which operate at high speeds, induce less distortion in the material, and it is expected that punching will be used extensively in the future. The punching is approved for material up to $25 \mathrm{~mm}$ in thickness provided that the hole diameter is not less than thickness of the material, if there is no other specification. The burrs should be removed from the holes before the assembly. It can be omitted when the holes are drilled in one operation through parts clamped together, which would not be separated after drilling. The gas and plasma cutting may also form the holes. In this case, similarly to fast drilling/punching, influence on material properties has to be studied experimentally.

The design requirements limit the bolt end and pitch distances; see Fig. 2. The short slotted holes may not be greater than $(d+2) \mathrm{mm}$ by $(d+6) \mathrm{mm}$ [1]; the long slotted holes not greater than $(d+2) \mathrm{mm}$ by $2,5 d$ [1]; and the extra large slots not greater than $(d+2) \mathrm{mm}$ by 3,5 $d$ according to British design practice for M16 and M24 bolts.

The connections with more bolts have been tested at the CRIF laboratory in Liege [2]. The plates were connected with bolts in each hole of the plate made by different technology. Very long slotted holes were experimentally investigated at University of Nottingham [3] and [4]. The behaviour of each particular component was observed in test at the Czech Technical University of Prague [5]. The double cover plates were used with only one bolt in an internal/external position. The tests results of bolted connections of the curtain wall connections with slots at different inclination compare to the acting force [6] are concluding the presented findings. The experiments with aluminium connections are available in the study by Gitter [7]. The study exhibits similar results, because the main structural disadvantage of low ductility of aluminium alloys is reduced by slotted holes with higher deformation capacity, see Fig. 1. The design prediction model of stiffness, resistance, and deformation capacity by component method was prepared at Czech Technical University with cooperation of Blaise Pascal University, Clermont-Ferrand. 


\section{DESIGN RESISTANCE}

Resistance of bolted connections loaded by shear force in plane of the plates is limited by bolt failures in shear and in bearing. When high strength friction bolts are used and no slip is allowed, bearing resistance is checked at ultimate limit state to eliminate the end shear failure. The bearing resistance represents the resistance of internal and external bolts in most design procedures. Based on experimental evidence, shear and bending type of failure may be recognised on the bearing failure. The bearing resistance is reduced in case of slotted holes. The reduction factor for resistance applied in draft of European standard prEN 1993-18 (2002) is based on latest experiments [2], [4], and [5]. The tests were carried out to learn not only the resistance, but also the deformation stiffness and the deformation capacity. The resistance of bolted connections may be evaluated by four basic concepts. The ultimate experimental resistance $F_{\text {exp; } \text {; }}$ depends strongly on the failure mode. For the design is used rarely. It needs to be equipped by separate check at the serviceability limit state and the ductile behaviour has to be assured. The traditional background of most codes indicates the resistance $F_{\text {exp; } 1,5}$ limited by deformation of $1,5 \mathrm{~mm}$. The resistance for the structural members obtained from the tests to failure $F_{\text {exp;yy fum }}$ is evaluated by reducing the resistance from structural material strength $f_{u m}$ to the characteristic yield strength $f_{y}$. The procedure described in Annex Y [8] as $F_{\text {exp; } ; y / f u m}=0,9 F_{\text {exp;ult }} f_{y} / f_{\text {um }}$ for the cases if the brittle rupture occurs. The conventional (elastic) limit of resistance $F_{\text {exp;conv }}$ defines the resistance as the intersection of a straight line with the initial stiffness and of a straight line having the slope equal to stiffness divided by ten, which drawn as a tangent to the non-linear part of the curve, see Fig. 3. The conventional resistance depends more on the joint stiffness than on the failure type. The Technical Committee for Structural Joints of the European Convention for Constructional Steelwork recommended the conventional resistance for evaluation of tests with bolts in slotted holes by at its meeting in Roanoke on October $20^{\text {th }}, 2000$. The difference up to $7,5 \%$ between conventional resistance $F_{\text {exp;conv }}$ and resistance reduced to the yielding of material $F_{\text {exp;fy/fum }}$ was observed at available tests based on the particular failure mode. The prediction of bearing resistance is simplified in expression, see in [1],

$$
F_{b . R d}=\beta_{r} \frac{2,5 \alpha f_{u} d t}{\gamma_{M b}},
$$

where $\alpha$ is the smallest of 


$$
\frac{e_{1}}{3 d_{o}} ; \frac{p_{1}}{3 d_{o}}-\frac{1}{4} ; \frac{f_{u b}}{f_{u}} \text { or } 1,0
$$

$\gamma_{M b}$ is the partial safety factor for bolts; $\beta_{r}$ is a reduction factor for resistance. Annex Z [9] provides a standard procedure, see [10] and [11], for determining partial safety factors from the results of tests. The number of test with slotted holes available is limited to 70. It is a restricted number compare to the number of tests in background documents [10]. The Annex $\mathrm{Z}$ model allows values of different tests to be compared. The variation in the prediction of the design model is determined from the tests (in term $d$ ). This variation is combined with variations of the other variables in the resistance function, with the variation in material strength and stiffness and variation in geometrical properties. Not all the variations in geometrical properties and in strength were accessible for slotted hole tests and assumptions have to be made for the error term. The calculation of the error term is using the data available ([5] and [12]) and is extended to all tests. The tests with repeated loading in [5] were not taken into the statistical evaluation. The theoretical resistance $r_{t . i}=F_{b . R d}$ was compared to the experimental value $r_{e i}$ from the tests. The points representing pairs of corresponding values $\left(r_{t i}, r_{e i}\right)$ are plotted on Fig. 4 . The reduction factor $\beta_{r}$ is summarized in Tab. 1. The factor $\beta_{r}$ for the full set is below factor for very long slot due to limited variation. The factor introduces higher errors, which are responsible for this low variation of the reduction factor $\beta_{r}$. The variation underlines the importance of division of the set into three sub-sets in order to predict more accurate results.

\section{DESIGN STIFFNESS}

The application of the component method requires three basic steps: listing of the joint components, evaluation of force-deflection diagram of each individual component, in terms of initial stiffness, strength and deformation capacity, and assembly of the components in view to evaluate the whole joint behaviour. The stiffness, the resistance and the deformation capacity are assembled separately for simplicity. The cover plate connections may be dismantled into the components: plate in tension, bolts in shear, and bolts in bearing. The behaviour of each component may be predicted by bilinear model. Zoetemeijer [13] described the stiffness of components of the end plate joints based on non-linear prediction known from its resistance. The prediction of the stiffness at the elastic stage was first applied 
by Wald and Steenhuis [14] to simplify the model. A concentrated research of bolted angle cleats with un-threaded non-preloaded bolts in circular holes was finalised by Jaspart [14] including a full description of the component behaviours. The results are explored in European design practice; see ENV 1993-1-1 (1998) [9]. The initial stiffness of the component bolt/plate in bearing is calculated in the format

$$
k_{b, j, k}=\frac{F_{b, j, k}}{E \delta_{b, j, k}}=\beta_{s} \frac{24 n_{b} k_{b} k_{t} d f_{u}}{E}
$$

in $m m$, where $F_{b, j, k}$ is force in the component $j, k$ in bearing, $E$ modulus of elasticity, $\delta_{b, s, j}$ is deformation of the component $j, k$ in bearing, $k_{b}=k_{b 1}$ is but $k_{b} \leq k_{b 2} ; k_{b 1}=0,25 e_{b} / d+0,5$ but $k_{b 1} \leq 1,25 ; k_{b 2}=0,25 p_{b} / d+0,375$ but $k_{b 2} \leq 1,25$; and $k_{t}=1,5 t_{j} / d_{M 16}$ but $k_{t} \leq 2,5$. Prediction of stiffness of the bolts with thread in shear plane in circular bolt holes was evaluated on test by Mazura [5] based on the measured values of geometry and materials, see Fig. 6. The reduction of the initial stiffness due to the thread may be assumed as $\beta_{S}=0,75$, see [12] Fig. 7. The bearing of the bolt/plate consists of two modes shear and bearing, which is visible on failure Fig. 2. Analytical models may describe these mechanisms in elastic stage based on the slot geometry. The decline of stiffness due to the slot is for limited accuracy of the method for practical applications approximated by stiffness reduction factor $\beta_{s}=0,50$ based on experimental results in [12] Fig. 8. The elastic stage is limited in the joint modelling at $2 / 3$ of the design resistance of the individual component or the joint assembly [12]. For component in bearing the linear prediction was explored by the second stiffness with inclination $1 / 10$ of the initial one, see Fig. 9 and Fig. 10.

\section{ASSEMBLING}

Based on the behaviour of each component the assembly may be provided based on the joint geometry, see [16]. The assembling is shown at Fig. 5 for three bolt rows. The compatibility conditions are for instance:

$$
\begin{aligned}
& F_{c 2}=F_{c 1}+F_{b 2} \\
& F_{p 1}=F_{p 2}+F_{b 2}
\end{aligned}
$$




$$
\begin{gathered}
\delta_{b, p, 1}+\delta_{s, 1}+\delta_{b, c, 1}+\delta_{T, c, 1}=\delta_{T, p, 2} \\
\delta_{b, p, 2}+\delta_{s, 2}+\delta_{b, c, 2}+\delta_{T, c, 2}=\delta_{T, p, 3}
\end{gathered}
$$

The total acting force is calculated as

$$
F=F_{b 1}+F_{b 2}+F_{b 3}
$$

The connection elongation is

$$
\delta=\delta_{T, p, e}+\delta_{b, p, l}+\delta_{s, l}+\delta_{b, c, l}+\delta_{T, c, 1}+\delta_{T, c, 2}+\delta_{T, c, e}
$$

With the set of equations (4) till (9), the unknowns are calculated at each load step by spreadsheet, provided that the force-deflection diagram of each component is described. For more than three bolt rows a FEM code is utilised to assembly the diagrams represented as non-linear springs of the components into the connection, including the gaps represented to the manufacturing tolerances. The predicted stiffness of components was evaluated on tests with one bolt only, see Fig. 6, 7, and 8. The components are in this case in series. The total deformation stiffness $k_{t o t}$ of the connection is evaluated as

$$
\frac{1}{k_{t o t}}=\frac{1}{k_{T, p}}+\frac{1}{k_{b, p, 1}}+\frac{1}{k_{s, 1}}+\frac{1}{k_{b, c, 1}}+\frac{1}{k_{T, c}}
$$

The good prediction of stiffness in case of slotted holes is illustrated at Fig. 7 and 8 based on measured values of geometry and of material properties. For the test of connections, see [2], the stiffness was calculated based on the characteristic values of the test set up geometry and the measured characteristics of the plate material. On Fig. 9 and Fig. 10 are compared the predicted force-deformation diagrams to the experimental values. The prediction was prepared based on the design model, using yield strength $f_{y m}$ as well as for ultimate model based of strength $f_{u m}$. The non-linear part of the curve is simulated by linear approximation at $2 / 3$ of the design resistance till $3 \delta_{e l}$. The prediction of stiffness and of resistance shows good accuracy of the presented model. The accuracy of the deformation capacity using simple assumptions described in [17] is limited. The model gives 
a conservative prediction of the available experiments, but the safety level is not included into the deformation capacity yet.

\section{TOLERANCES}

The influence of erection tolerances was observed on model of connections with eight bolts M16-8.8 in plate P16-800 of steel S275 with the standard pitches $50 \mathrm{~mm}$. The first and the last bolts are in contact. The gap of $2 \mathrm{~mm} ; 1,5 \mathrm{~mm} ; 0,5 \mathrm{~mm}$; and $0 \mathrm{~mm}$ was simulated by the internal bolts. The influence of the tolerances is shown on the Fig. 12 at the distribution of the bolt forces during the loading. The bolt forces are reported in column diagrams for different assumptions of the gap of internal bolts. In one diagram are collected force distributions for different gaps under one loading step represented by the connection total deformation. The deformation capacity of the joint eliminates the unfavourable influence of tolerances in cover plate connection [18] in case of the less ductile circular holes. The resistance may decrease in case of a qualitative change from the ductile mode in the bearing failure into the brittle one in case of the bolt shear failure; by designing the thick cover plates with small bolt diameter and very long bolt pitches.

\section{CONCLUSIONS}

Bolted connections with slotted holes perpendicular to the acting force exhibit lower stiffness and higher deformation capacity compare to connections with circular holes.

Due to the lower stiffness, a lower design resistance is incorporated into the proposal of EN 1993-1-8 based on common work at Liege [2], Nottingham [4], and Prague [5]. A conservative assumption incorporates a reduction factor $\beta_{r}=0,60$ of the design bearing resistance for design practice [1].

Component model of the cover plate connection, which is included in ENV 1993-11/A2 (1998) [1] and [8], enables to simulate the influence of the tolerances and the length in the connections with a good accuracy.

Prediction of the stiffness of bolts presented by Jaspart [14] for untreated bolts in bearing may be extended to the fully threaded bolts as well as to the bolts in slotted holes. 


\section{ACKNOWLEDGEMENTS}

The authors dedicate this work to Mr. Martin Steenhuis, who brought great ideas into the structural connection design. This research has been supported by the J01-98:210000004 grant from the Czech Ministry of Education, Youth and Sports and by the Barrande grant N²001-051-2 between France and Czech Republic. 


\section{LIST OF SYMBOLS}

The Eurocode system of symbols is applied to the paper.

d nominal bolt diameter

$d_{M 16} \quad$ diameter of bolt M16

$e_{b} \quad$ distance form the bolt row to the free edge of the plate in direction of load transfer

$f_{u} \quad$ characteristic strength of plate

$f_{u m} \quad$ average ultimate strength taken from tested plate

$f_{y} \quad$ characteristic yield strength of plate

$f_{y} \quad$ average yield strength taken from tested plate

$g \quad$ gap

$k_{b, p}, k_{b} \quad$ stiffness of component bolt/plate in bearing

$k_{b 1} ; k_{b 2} ; k_{t} \quad$ partial stiffness of component bolt/plate in bearing

$k_{\text {tot }}$

$n_{b}$

deformation stiffness of connection

number of shear planes of bolt

$p_{b} \quad$ spacing of bolt rows in direction of load transfer

$r_{e i} \quad$ experimental resistance

$r_{t . i} \quad$ theoretical resistance

$t_{j} \quad$ thickness of the plate

E modulus of elasticity

$F \quad$ force

$F_{\text {exp;conv }} \quad$ conventional (elastic) limit of resistance

$F_{\text {exp;yyffum }}$

$F_{\text {exp; ult }}$

resistance reduced to characteristic yield strength

ultimate resistance of experimental

$F_{\text {exp;1,5 }} \quad$ resistance limited by deformation of $1,5 \mathrm{~mm}$

$F_{i, j, k} \quad$ force in component $i, j$ in bolt row $k$

$\beta_{r} \quad$ reduction factor for resistance

$\beta_{s} \quad$ reduction factor for stiffness

$\delta_{e l} \quad$ deformation at elastic limit

$\delta_{i, i, j} \quad$ deformation of component $i, j$ in bolt row $k$

$\gamma_{M b} \quad$ partial safety factor for bolts

Subscripts

$\begin{array}{ll}b & \text { bolt/plate in bearing } \\ c & \text { cover plate } \\ p & \text { plate } \\ s & \text { bolt in shear } \\ T & \text { plate in tension } \\ 1,2,3 & \text { number of bolt row }\end{array}$




\section{REFERENCES}

[1] prNV - 1993-1-8, Eurocode 3: Design of Steel Structures, Part 1.8 - Design of joints, Stage 34 draft, CEN, Brussels 2002. p.124.

[2] Piraprez E. Behavior of plates with slotted holes - CRIF Belgium, Proceeding of International Conference on Steel Structures of the 2000's, IABCE, Istanbul 2000.

[3] Tizani, W.: The Bearing Capacity of Plates Made with Long-slotted Bolt Holes, SCI reference - BCC831, pp.1-40, London 1999.

[4] Owens, G.W., Nethercot, D.A., Tizani, W.: The Bearing Capacity of Slotted Holes, SCI reference - Document RT755, Version 02, pp.1-40, London 1999.

[5] Wald F., Mazura V., Moal V., Sokol Z.: Experiments of bolted cover plate connections with slotted holes, CTU reports, Vol. 2, 2/2002, CVUT, Prague 2002, p. 79-97, ISBN 80-01-02536-8.

[6] Kersten O.: Zum Last-Verschiebungs-Verhalten geschraubter Scher-LochleibungsVerbindungen im Stahlbau unter statischer Belastung, Dissertation, TU HamburgNamburg, Hamburg 1997, p.111.

[7] Gitter R., Piraprez E., Sedlacek G., Schneider R.: Lochleibungsfestigkeit von Schraubenverbindungen mit Langlöchern, DASt Forchungsbericht, Aachen 2001, p.15.

[8] ENV - 1993-1-1: Design of Steel Structures - General rules and roles for buildings, European Prenorm, CEN, Brussels 1992, p.344.

[9] ENV - 1993-1-1/A2: Design of Steel Structures - General rules and roles for buildings, Annex J, Annex Z, CEN, Brussels 1998, p.116.

[10] Bijlaard F.S.K., Sedlacek G., Stark J.W.B.: Procedure for the determination of design resistance from tests, Background report to Eurocode 3, BI-87-112, Delft 1988.

[11] Snijder H. H., Ungerman D., Stark J.W.B., Sedlacek G., Bijlaard F.S.K., HemmertHalswick A.: Evaluation of test results on bolted connections in order to obtain strength functions and suitable model factors, Part B: Evaluation, Background documentation, 6.02, BI-88-087, Delft 1988.

[12] Moal M.: Assemblages avec trous oblongs et boulons non-precontraints, Diploma work, CUST, Départment Génie Civil, Université Blaise Pascal, Clermont-Ferrand, 2001.

[13] Zoetemeijer P.: Summary of the Research on Bolted Beam-to-Column Connections (period 1978 - 1983), Rep. No. 6-85-M, Steven Laboratory, Delft 1983.

[14] Wald F., Steenhuis M.: The Beam-to-Column Bolted Joint Stiffness according Eurocode 3, in Workshop 1992 - COST C1, Proceedings of the State of the Art Strasbourg 1993, pp.503-516.

[15] Jaspart J.P.: Recent advances in the field of steel joints - Column bases and further configurations for Beam-to Column Joints and Beam Splices, Thesis, Université de Liège, Liège 1997, p.246.

[16] Gresnigt A.M., Steenhuis C.M.: Stiffness of lap joints with preloaded bolts, in The Paramount Role of Joints into the Reliable Response of Structures, NATO Science Series, ed. Banitopoulos C.C., Wald, F.: Series II, Vol. 4, Kluver Academic Publishers, Dortrecht 2000, ISBN 0-7923-6700-6, pp.396-408.

[17] Wald F., Mazura V., Moal V., Sokol Z.: Component method for bolted cover plate connections with slotted holes, in International Colloquium on Stability and Ductility of Steel Structures, Budapest 2002, pp.587-594, ISBN 963-05-7950-2.

[18] Zygomalas, M., Kontoleon M.J., Banitopoulos C.C.: A hemivariation inequality approach to the resistance of the aluminium riveted connection, in $6^{\text {th }}$ national congress of mechanics, ed. Kounadis A.N., Thessaloniki 2001, p.70-77. 


\section{List of tables}

Tab. 1 Application of Annex Z [9] on different sub-sets [12]

\section{$\underline{\text { List of figures }}$}

Fig. 1 Comparison of typical force - displacement diagrams of test with slotted holes (test 5C-16-1-2,5 d) to circular holes (test 1C-16-1-d+2) [5]

Fig. 2 a) Slotted hole recommended geometry [2]; b) shear bearing failure (test 1C - 16-1-d+2 [5]); c) bending bearing failure (test 5C - 16-1-2,5 d [5])

Fig. 3 Limits of the resistance of joint; deflection limit $F_{\text {exp } 1,5}$; ultimate limit $F_{\text {exp;ult }}$; conventional limit $F_{\text {exp;conv }}$; reduced limit by steel yield ratio $F_{\text {exp;fy fum }}$; test I 1-3 (16 - 1 - 2,5d) [4]

Fig. 4 Influence of the slot length in the plate failure [12]

Fig. 5 Assemblage of components, an example of case with three bolts rows in cover plate

Fig. 6 Evaluation of model to tests with circular bolt holes, test 16-1-d+2 [5]

Fig. 7 Evaluation of model to the test with bolts in slotted holes, tests 16-1-2,5 d [5]

Fig. 8 Evaluation of the prediction model to test with bolts in long slotted holes, tests $16-1-3,0 \mathrm{~d}[5]$

Fig. 9 Comparison between model and experiments [2], tests with bolts M16

Fig. 10 Comparison between model and experiments [2], tests with bolts M27

Fig 11. Influence of gap of internal bolts of cover plate bolted connection with slotted holes; prediction by component method, plate P16-800 S275; 8 M16-8.8; pitches $50 \mathrm{~mm}$

Fig. 12 Distribution of bolt forces during loading (represented by deformation of connection $\delta$ ) for variable gap of internal bolts; prediction by component method, the external bolt is in contact; plate P16-800 S275; 8 bolts M16-8.8; bolt pitch $50 \mathrm{~mm}$ 
Tab. 1 Application of Annex Z [9] on different sub-sets [12]

\begin{tabular}{|c|c|c|c|c|}
\hline Set & All test specimens & $\begin{array}{c}\text { Normal and } \\
\text { short slotted holes }\end{array}$ & Long slotted holes & Very long slotted holes \\
\hline From & $d+2 \mathrm{~mm}$ & $d+2 \mathrm{~mm}$ & $2 d$ & $3,125 d$ \\
To & $3,5 d$ & $d+6 \mathrm{~mm}$ & $2,5 d$ & $3,5 d$ \\
Number of test & 61 & 15 & 39 & 7 \\
$\gamma_{R}^{*}$ & 2,14 & 1,34 & 1,76 & 2,05 \\
\hline$\beta \boldsymbol{r}$ & $\mathbf{0 , 5 8}$ & $\mathbf{0 , 9 3}$ & $\mathbf{0 , 7 1}$ & $\mathbf{0 , 6 1}$ \\
\hline
\end{tabular}

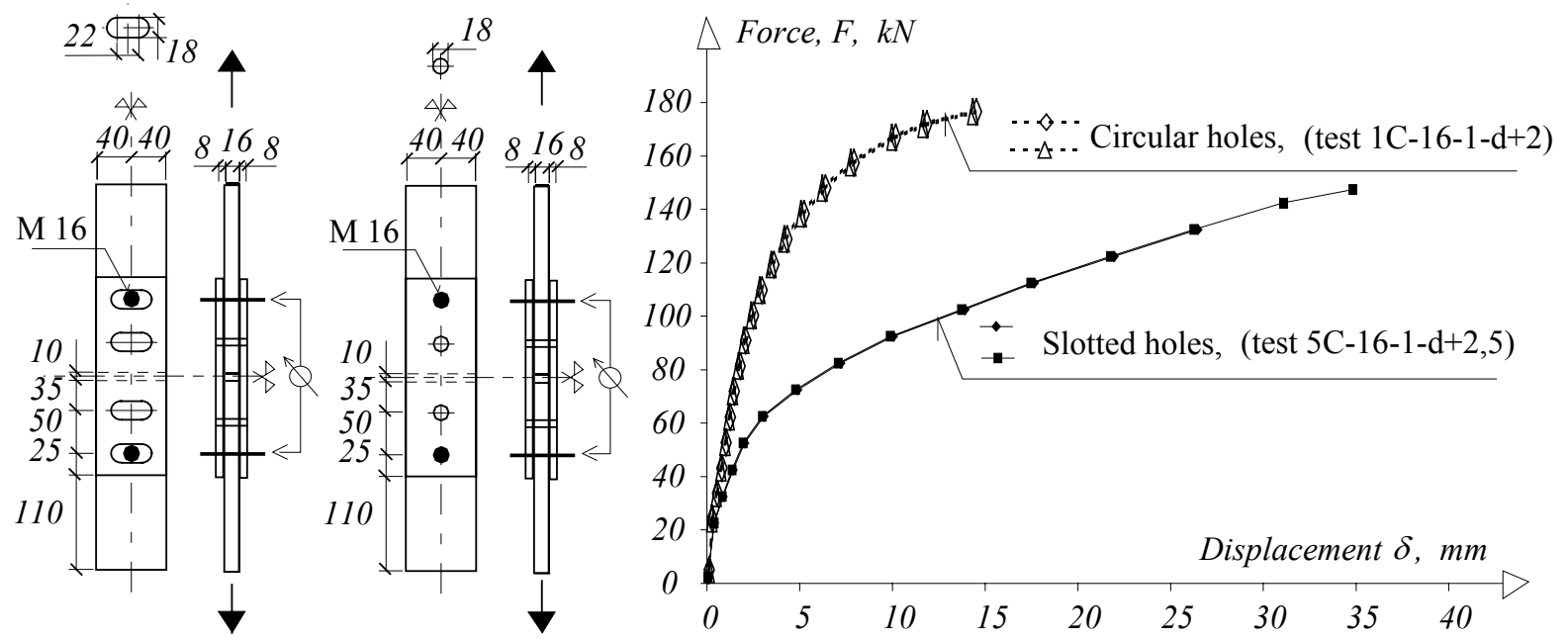

Fig. 1 Comparison of typical force - displacement diagrams of test with slotted holes (test 5C - 16-1-2,5 d) to circular holes (test 1C - 16-1-d+2), [5] 

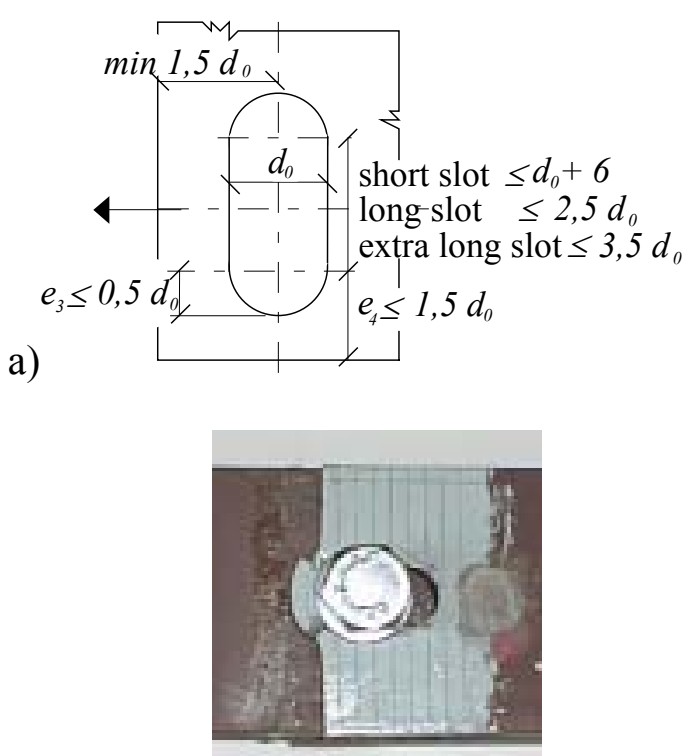

b)

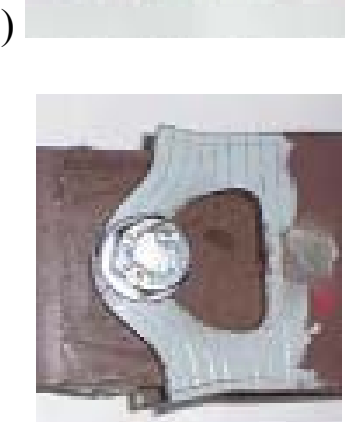

c)

Fig. 2 a) Slotted hole recommended geometry [1]; b) shear bearing failure (test 1C - 16-1-d+2 [5]); c) bending bearing failure (test 5C - 16-1-2,5 $d$ [5])

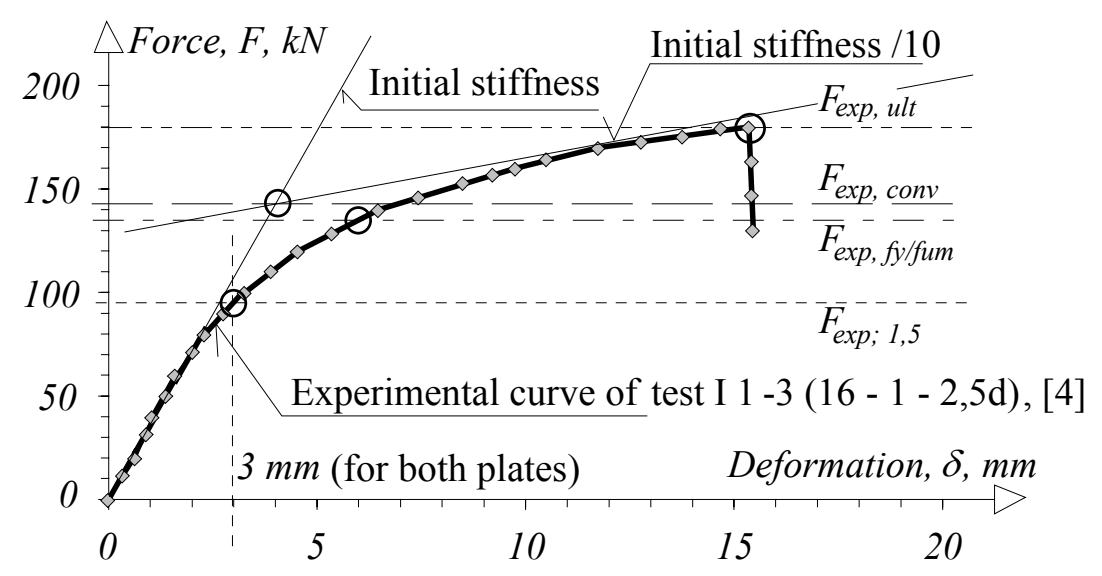

Fig. 3 Limits of the resistance of joint; deflection limit $F_{\text {exp } ; 1,5}$; ultimate limit $F_{\text {exp } u l t}$; conventional limit $F_{\text {exp;conv }}$; reduced limit by steel yield ratio $F_{\text {exp;fy/fum }}$; test I 1-3 (16-1 - 2,5d) [4] 


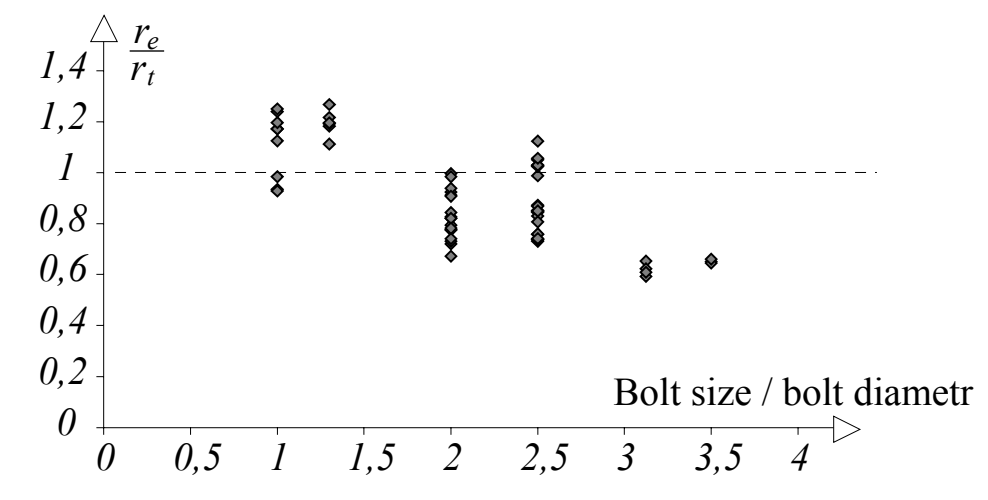

Fig. 4 Influence of the slot length in the plate failure [12]

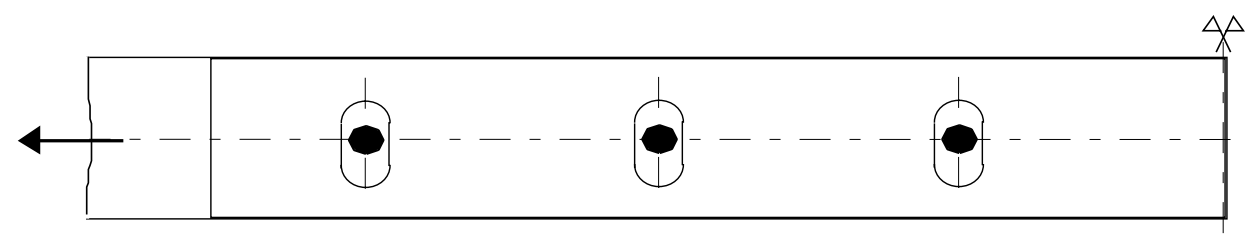

Cover

plate

connection

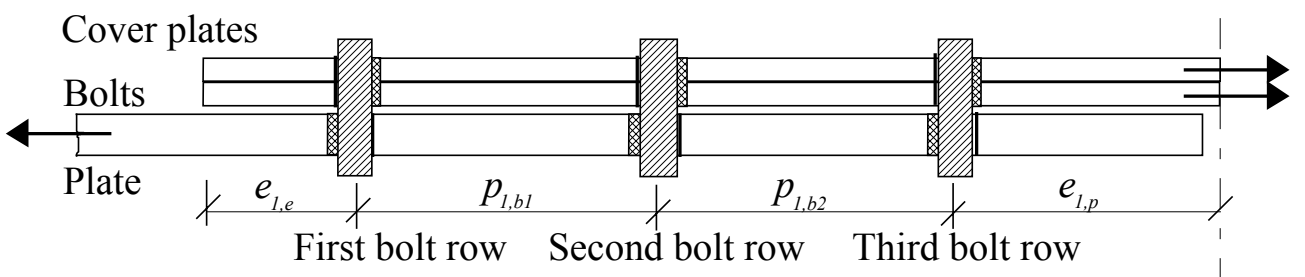

Geometry

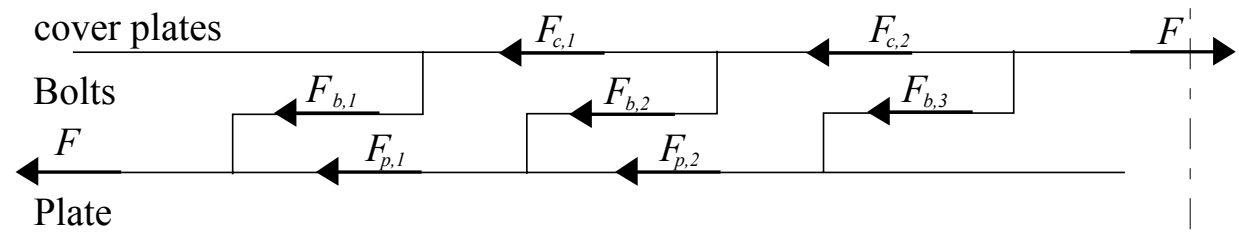

Internal

forces

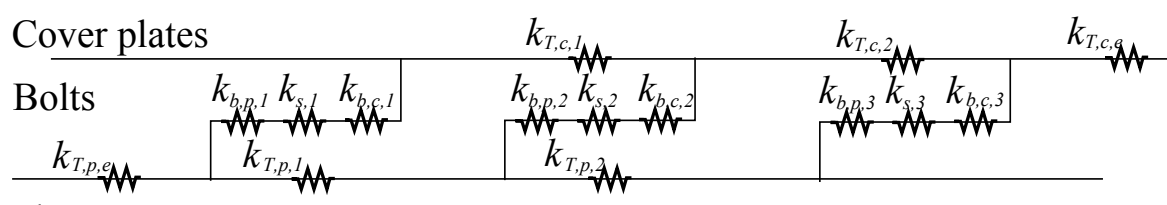

Mechanical (spring) model Plate

Fig. 5 Assemblage of components, an example of case with three bolts rows in cover plate 

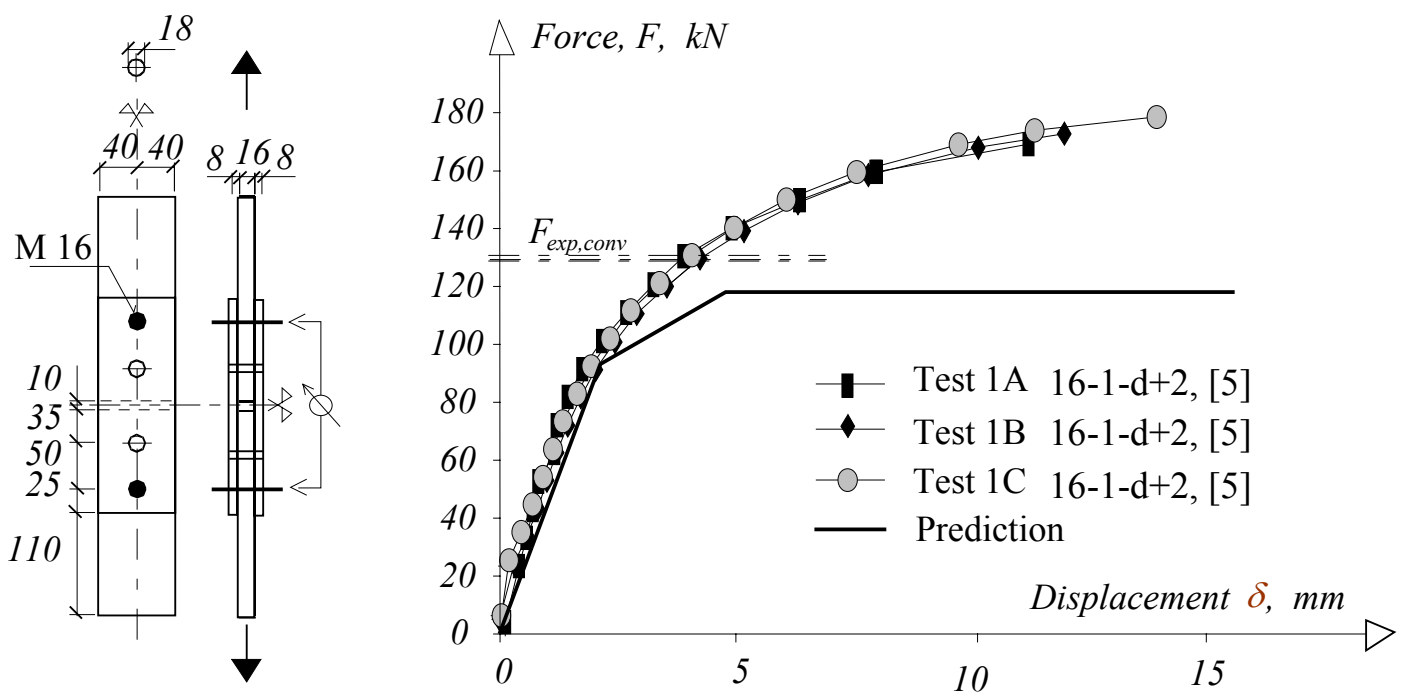

Fig. 6 Evaluation of model to tests with circular bolt holes, test 16-1-d+2 [5]
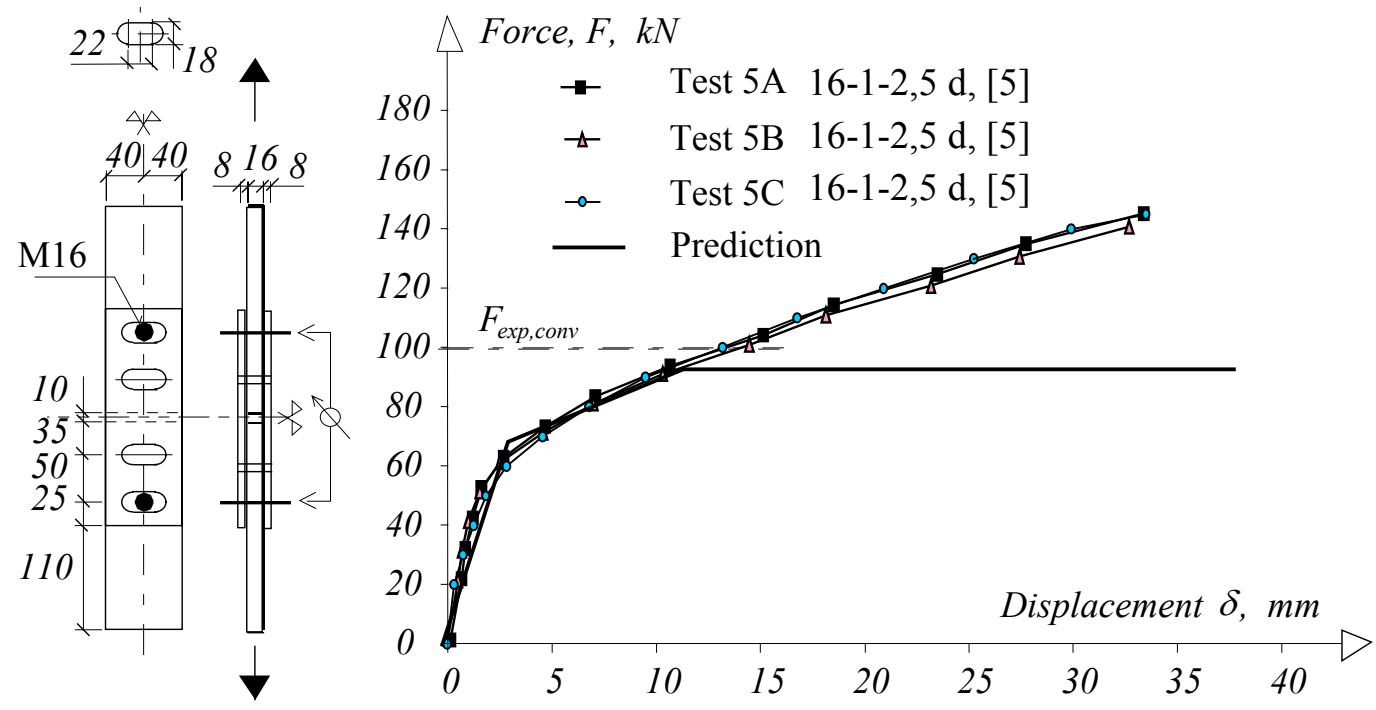

Fig 7. Evaluation of model to the test with bolts in slotted holes, tests 16-1-2,5 d [5] 

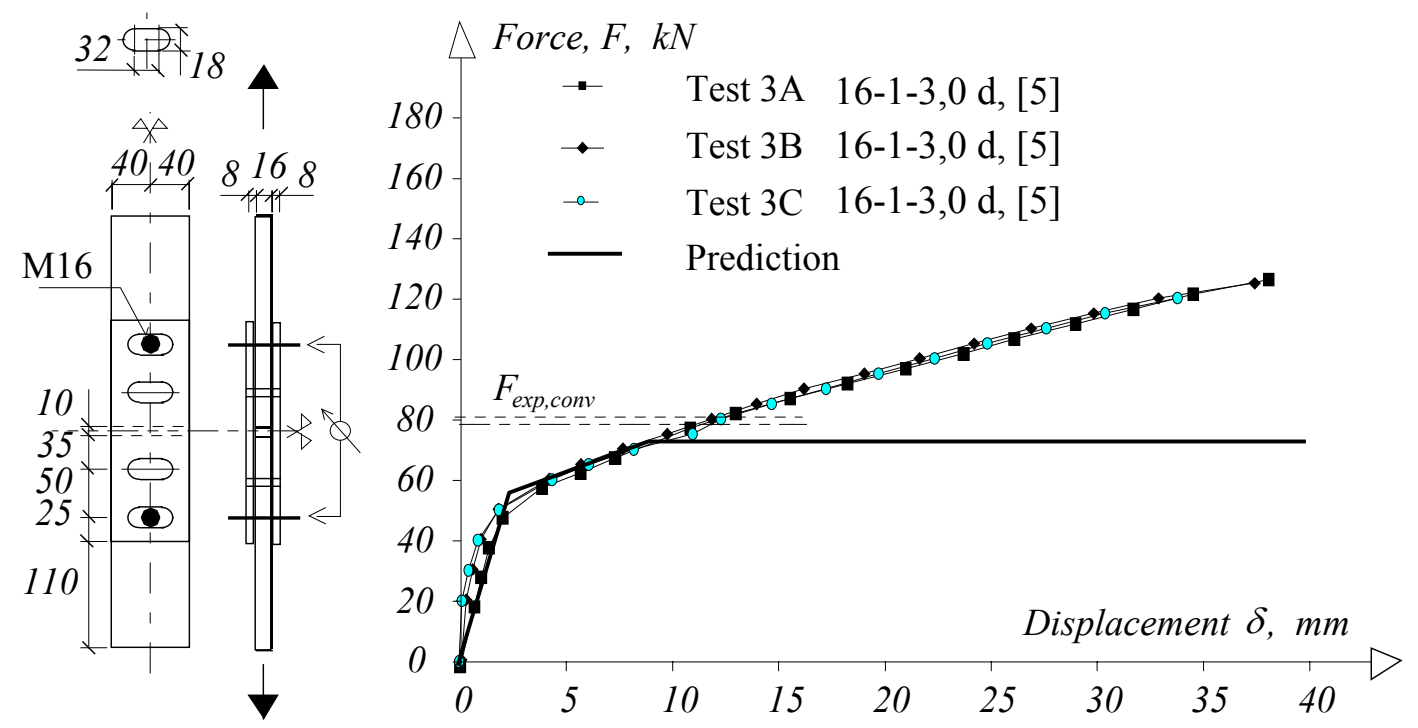

Fig. 8 Evaluation of the prediction model to test with bolts in long slotted holes, tests $16-1-3,0 \mathrm{~d}[5]$

Force, $F, k N$

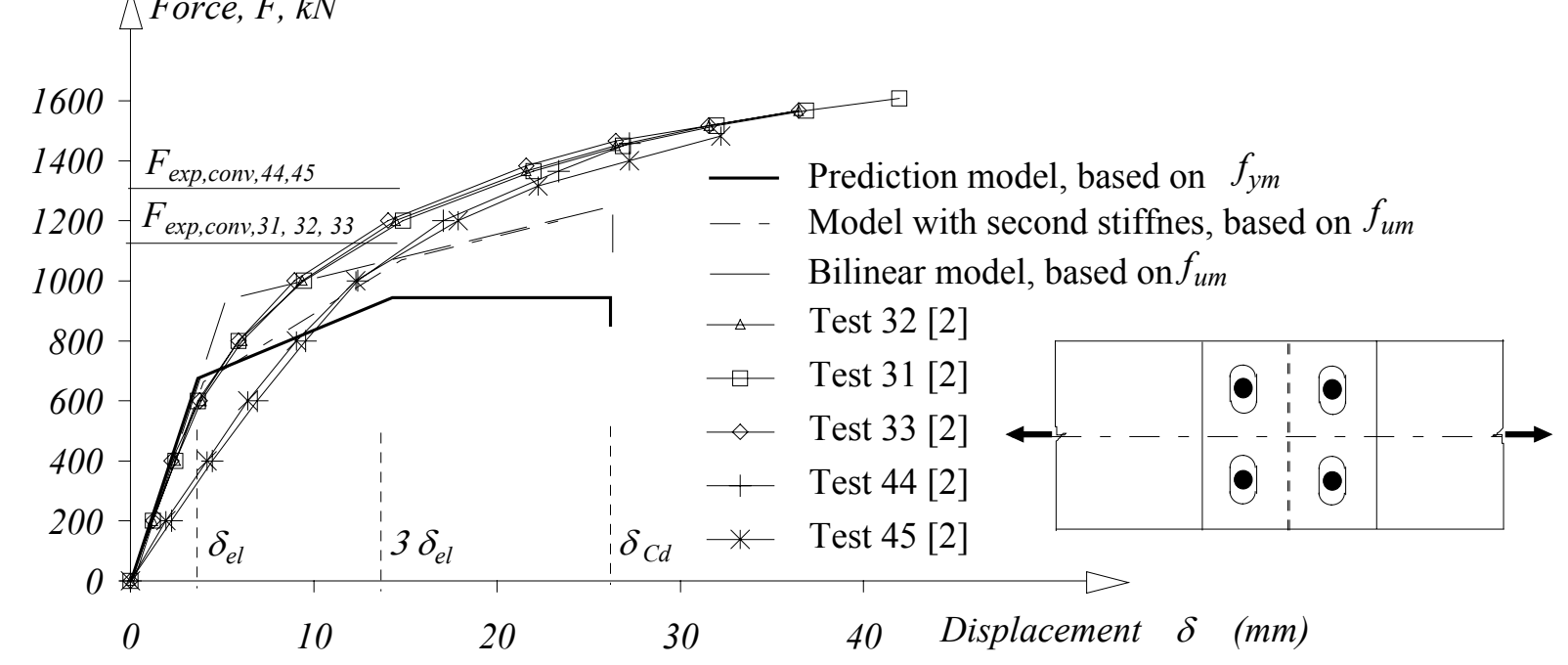

Fig. 9 Comparison between model and experiments [2], tests with bolts M16 


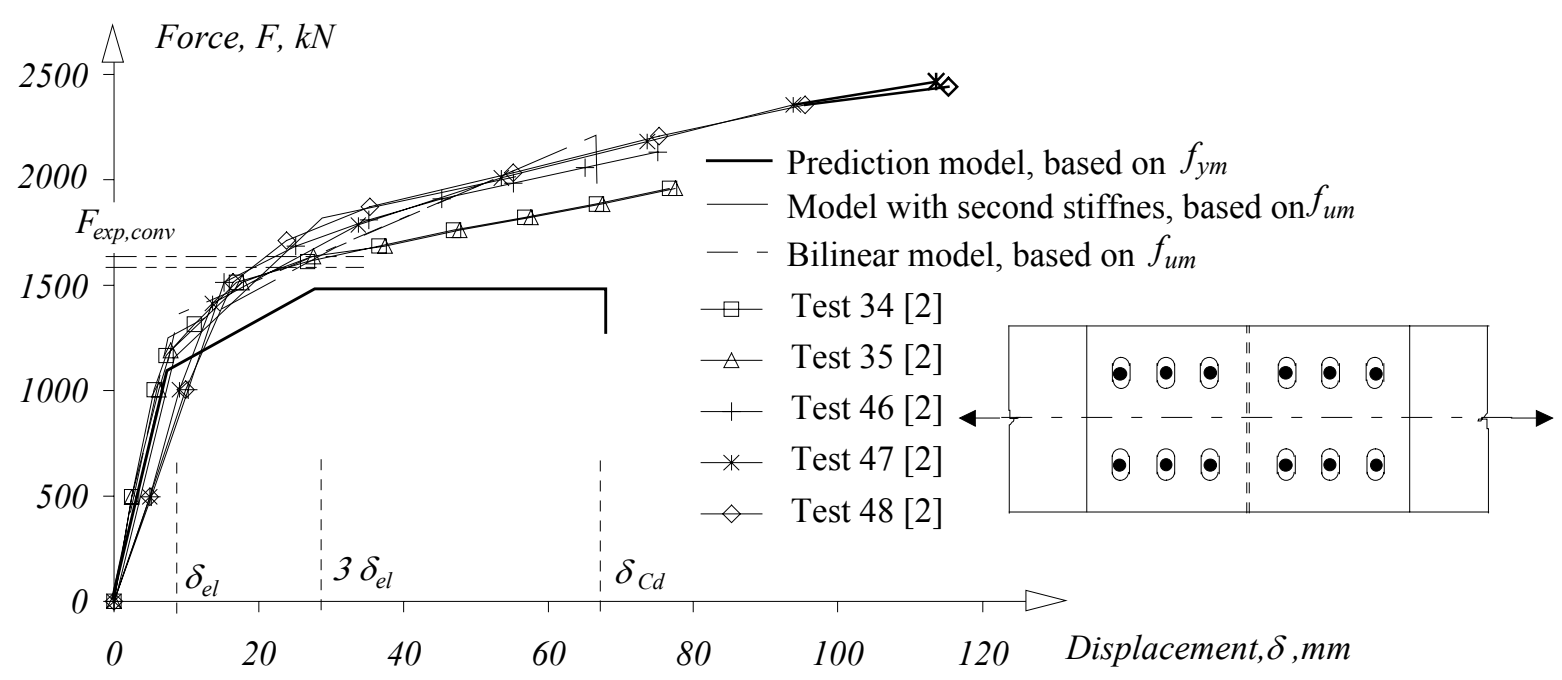

Fig. 10 Comparison between model and experiments [2], tests with bolts M27

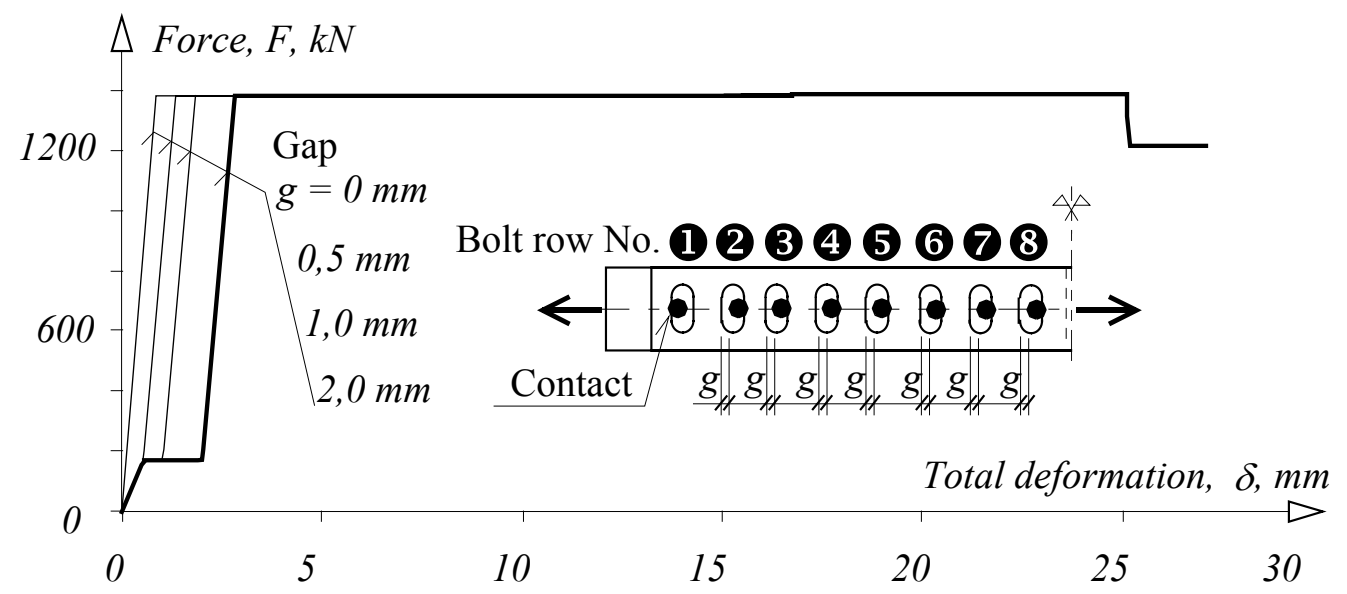

Fig 11. Influence of gap of internal bolts of cover plate bolted connection with slotted holes; prediction by component method, plate P16-800 S275; 8 M16-8.8; pitches $50 \mathrm{~mm}$ 

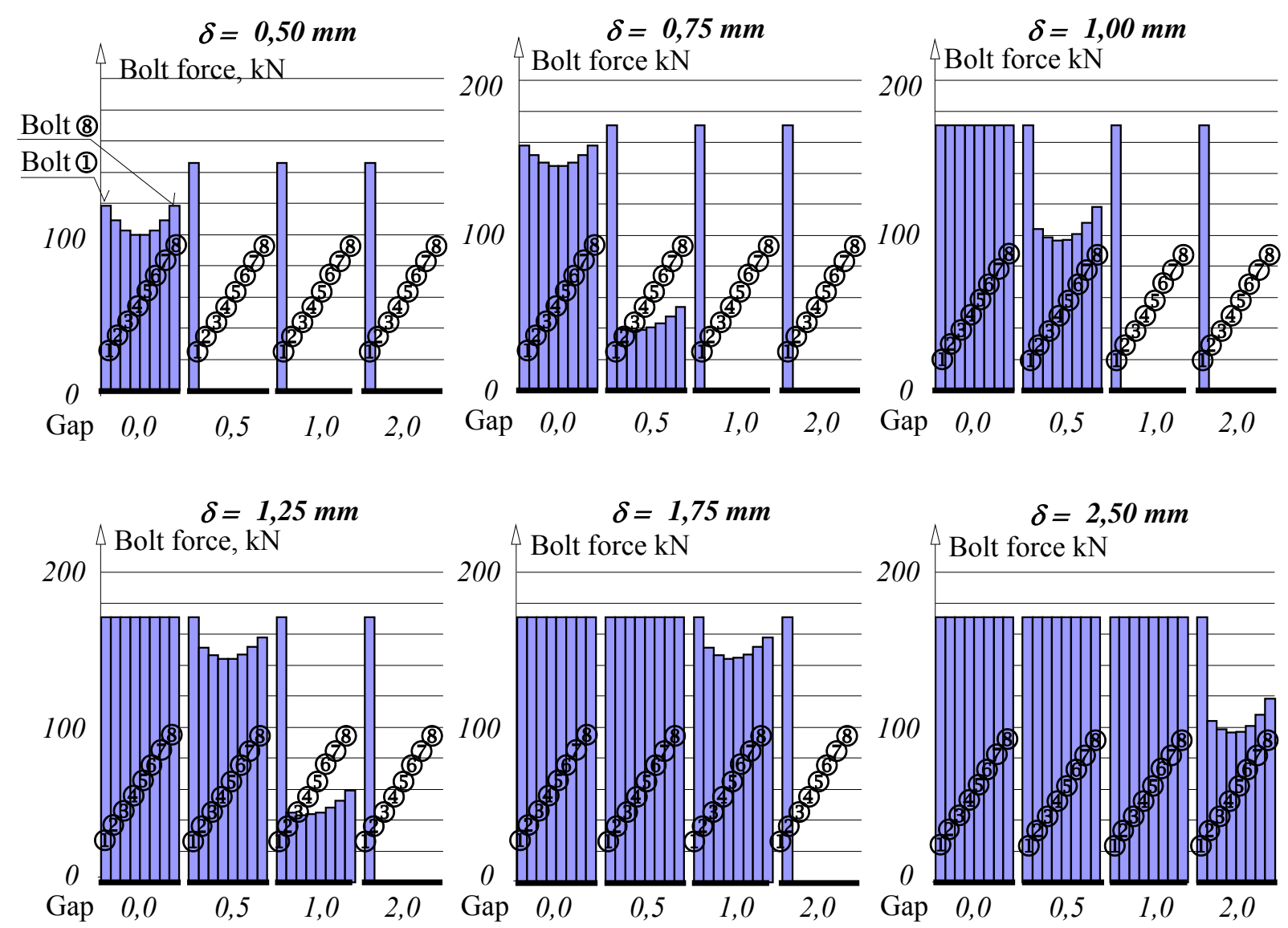

Fig. 12 Distribution of bolt forces during loading (represented by deformation of connection $\delta$ ) for variable gap of internal bolts; prediction by component method, the external bolt is in contact; plate P16-800 S275; 8 bolts M16-8.8; bolt pitch $50 \mathrm{~mm}$ 